\title{
Gender Differences in the Level of Engagement with Mathematics Support in Higher Education in Ireland
}

\author{
Eabhnat Ní Fhloinn ${ }^{1} \cdot$ O. Fitzmaurice ${ }^{2}$. \\ C. Mac an Bhaird ${ }^{3}$ - C. O'Sullivan ${ }^{4}$
}

Published online: 17 June 2016

(C) Springer International Publishing Switzerland 2016

\begin{abstract}
Over the past couple of decades, mathematics support centres have become widespread in higher education, most notably in Ireland, the U.K. and Australia. These centres generally offer a range of free support services to students who feel they need additional help with their mathematics modules. A major large-scale survey of first-year higher education students was undertaken in Ireland to ascertain students' evaluation of mathematics support. There were significant differences in self-reported attendance between male and female students, with a binary logistic regression model showing that female students were almost two and a half times more likely to engage with mathematics support than male students, while controlling for other factors such as prior mathematical achievement, degree, and institution attended. In this paper, the engagement levels of 1633 students with mathematics support across nine Higher Education Institutes are analysed. The reasons given by both genders for either using or not using the services provided across a range of disciplines and higher education institutes are explored, with the aim of ensuring that the optimum support is provided to all students who may need such help.
\end{abstract}

Keywords Gender $\cdot$ Mathematics $\cdot$ Support $\cdot$ Engagement $\cdot$ Attendance $\cdot$ Opinions

Eabhnat Ní Fhloinn

eabhnat.nifhloinn@dcu.ie

1 School of Mathematical Sciences, Dublin City University, Room X138A, Glasnevin, Dublin 9, Ireland

2 Department of Mathematics and Statistics, University of Limerick, Limerick, Ireland

3 Department of Mathematics and Statistics, Maynooth University, Maynooth, Ireland

4 Department of Mechanical Engineering, Institute of Technology Tallaght, Dublin, Ireland 


\section{Introduction}

Due to growing concern about the under-preparedness of incoming undergraduates to cope with the mathematical demands of their courses, many higher education institutes (HEIs) have implemented various forms of mathematics support, particularly aimed at first-year students (Gill et al. 2010). These supports typically take the form of mathematics support centres, which offer one-to-one help to students on a drop-in or appointment basis and are free of charge. Additional supports also on offer include online resources, revision classes, extra tutorials, mathematical software and so on. The widespread provision of mathematics support across HEIs in Ireland, the United Kingdom and Australia has been welldocumented in recent years (Perkin et al. 2012; Gill et al. 2008; MacGillivray 2008). Best practice guides are available for establishing mathematics support centres (Mac an Bhaird et al. 2012) and numerous papers have explored the effectiveness of such support services for students who engage with mathematics support, using a variety of approaches such as analysis of usage data (Croft 2000; Ní Fhloinn 2009; MacGillivray 2009), internal student questionnaires and focus groups (Parsons et al. 2011; Carroll and Gill 2012; Grehan et al. 2016), evidence from external sources such as the UK National Student Survey (results of which are available at http:/www.hefce.ac.uk/lt/nss/results/), and measures of the potential impact of mathematics support upon retention and performance (Pell and Croft 2008; Mac an Bhaird et al. 2009; Gill and O'Donoghue 2006) with overwhelmingly positive results overall. For a detailed review of these and other such research, see Matthews et al. (2012).

However, despite these supports being in place, there is an ongoing problem with non-engagement with mathematics support services by a certain cohort of "at-risk" students, where "at-risk" implies a student who, based on their mathematical achievements prior to attending university, would be deemed likely to struggle substantially with the mathematical content of their course. Although mathematics support services are generally open to any students who feel they need to attend (Pell and Croft 2008), non-engagement by at-risk students is a persistent concern.

While work has been undertaken to investigate students' reasons for nonengagement with mathematics support (notably in Symonds et al. 2008 and Grehan et al. 2011), the issue has not been considered from a gender perspective to date. Once prior attainment, discipline and level are taken into account, male and female students are equally likely to progress to the following year of study, but low prior mathematical attainment is a major cause of non-completion (McGuinness et al. 2012) and female students are less likely to choose to study STEM programmes, with $29 \%$ of degree awards across all levels in Ireland made to females in 2015 (www.hea.ie/node/1557). Possible gender differences in engagement levels are worthy of investigation to ascertain whether the forms of mathematics support currently on offer may be more attractive or accessible to students of one gender over the other. Given that mathematics support strives to provide support for all who need it, it is of paramount importance that it be perceived as such by at-risk students regardless of gender. Therefore, there are four main research questions that will be addressed in this paper:

(1) How does the level of engagement with mathematics support compare between male and female students, when controlling for factors such as degree programme, institution attended and prior mathematical achievements? 
(2) In what areas do male and female students report different reasons for using/not using mathematics support?

(3) What differing impacts upon themselves are reported by male and female students as a result of using mathematics support?

(4) How do responses given by male and female non-users of mathematics support differ when asked what might encourage them to engage with the service if needed?

\section{Background}

The use of mathematics support in higher education is generally at the student's own discretion; while certain students may be advised to use the service based on their level of mathematics upon entry, no extra credit is awarded for using the service and no penalties apply for failing to do so. If a student feels they need extra help, they are free to attend. It is important to note that this paper does not seek to explore whether gender differences in mathematics exist, but rather to investigate the use of mathematics support from a gender perspective. As a result, a large number of potentially influential factors come into play regarding an individual student's decision to self-refer to a mathematics support service. Some of these are easily measured, such as the availability, type and quality of the mathematics support in any individual institution as well as the discipline of study, the mathematical demands of the course and the student's prior mathematical achievements. Numerous reports exist on such data (see Mac an Bhaird et al. 2012 for details) and we shall not consider them further here. However, other influential factors are more difficult to quantify, but equally important, such as mathematical self-confidence; pre-examination anxiety; personal motivation, expectations and attitudes in relation to mathematics; peer-influence and so on. Much has been written on gender differences in each of these factors, particularly over the past 40 years. A good overview can be found in Fennema's discussion paper (Fennema 2000). While a full review of each factor is beyond the scope of this paper, we will now briefly highlight some of the most relevant work done in this area.

As early as 1987, Mura noted that, when asked to predict their final grades for their mathematics course, male undergraduates were more likely than female undergraduates to overestimate their grades (and female students were more likely to underestimate theirs), although the expectations of both genders were overly high (Mura 1987). More recently, Nurmi et al. (2003) echoed results first found by Fennema (1980) in secondlevel students, observing that, in relation to mathematics and at similar levels of achievement, male students displayed "remarkably" higher self-confidence than female students. Jones and Smart (1995), when faced with similar results among the teenage students they studied, subsequently found that "as a group, the girls had far more confidence in their female peers than they had in themselves as individuals" (Jones and Smart 1995, p. 164). Guimond and Roussel (2001) state that "women may be led to downplay their own performance in math while men may be led to brag about their relative success" (Guimond and Roussel 2001, p. 278), and go on to discuss how students seemed to rely on gender stereotypes rather than their own marks to selfevaluate in mathematics. Taken as an overall body of work, these studies point to the fact that female students are more likely to express lower self-confidence in relation to 
their own mathematical abilities. Given that students voluntarily use mathematics support, their perception of their mathematical ability can have a major impact on their decision to attend, whether this perception is high or low (Gillard et al. 2012).

Mathematics support centres tend to be busiest in the lead-up to the examination period. In their study of 300 high-school senior and university students, KosmalaAnderson and Wallace (2007) found that female students self-reported higher preexamination anxiety levels than male students. Similarly, a British study of over 400 secondary school students found that girls showed higher levels of both maths anxiety and test anxiety (Devine et al. 2012). In a Norwegian study comprising over 900 students ranging from about 10 years old to adult learners in high school, Skaalvik and Skaalvik (2004) looked at gender differences in self-concept, performance expectations and motivation in mathematics and found that male students of all ages in their sample had higher self-concept and in older age-groups had higher performance expectations. They conclude that "boys seem to judge themselves more favourably in mathematics than girls do as early as the end of elementary school" (Skaalvik and Skaalvik 2004, p. 249). Han and $\mathrm{Li}$ (2009) found in their study of 2,000 university students in China that the educational outcome of female students was influenced by their peers, but found no such evidence for male students. Mac an Bhaird et al. (2012) have noted the peer effect in mathematics support, observing that if students have a positive experience in mathematics support, they are likely to tell their peers.

Brandell and Staberg (2008) conducted a review of recent literature on the topic of mathematics as a "male domain" and concluded that, although some recent studies (Forgasz 2001; Leder 2001) have reversed the trend (finding a majority of second-level students perceive mathematics as gender-neutral), the majority of researchers have still shown that "mathematics is gendered as a male domain, both historically and currently" (Brandell and Staberg 2008, p. 499). The contrasting results from some different studies may be explained by Forgasz et al. (2004) who argue that, due to the different measurement scales used to determine gendered perception of mathematics, "it is not possible to argue definitively about change in attitudes over time" (Forgasz et al. 2004, p. 416). Brandell and Staberg agree, suggesting that "attitudes towards mathematics are not static but influenced by... development in school and society" (Brandell and Staberg 2008 , p. 498). The question remains as to whether the view of mathematics as a "male domain" impacts upon student attendance in mathematics support centres. It is therefore of interest to now explore whether evidence of any gender differences in relation to engagement with mathematics support is apparent in the results of our study, to ensure that the optimum support is provided to all students who require it.

\section{Methodology}

In 2009, the Irish Mathematics Learning Support Network (IMLSN) was established as an informal focus point for those interested in mathematics and statistics support in higher education in Ireland (Mac an Bhaird et al. 2011). Committee members are drawn from a range of HEIs from around the island. In order to ascertain student usage, experience and perceptions of mathematics support, the committee conducted a nationwide survey of first-year students on this issue. Surveys previously in use within HEIs to assess mathematics support were collected from IMLSN members, and 
questions from these were collated and adapted to form the basis of the large-scale survey. The questionnaire was anonymous and paper-based; there were 17 questions in total, with a variety of multiple-choice, five-point Likert-scale, and open-ended questions. Gender was not initially a primary focus of this survey, but all students were asked to contribute some personal information, which has subsequently allowed us to study results by gender and other categories. A pilot was conducted with approximately 100 students from four different institutes, and the survey was duly modified as a result of findings from the pilot. The full survey can be seen in the Appendix.

In February 2011, the survey was emailed by IMLSN committee members to a representative within each HEI in Ireland. They were invited to arrange for it to be printed and given to any first-year students who were studying at least one servicemathematics module (i.e. students who were studying at least one mathematics module as part of their degree programme, but were not specialising in mathematics), and return the completed surveys for analysis. The surveys were to be completed during mathematics lectures. As a result, the survey was carried out in nine HEIs, with five universities and four institutes of technology (IoTs) taking part, from a possible total of seven universities and 14 IoTs in Ireland ${ }^{1}$ (Higher Education 2013). The universities involved were Dublin City University, National University of Ireland Galway, Maynooth University, University College Dublin and University of Limerick. The IoTs involved were Institute of Technology Blanchardstown, Institute of Technology Carlow, Institute of Technology Tallaght and Institute of Technology Tralee. The survey was completed by 1633 first-year students during mathematics lectures, meaning that only those students who attended lectures on a given day would have had the opportunity to complete it. As such, this may have introduced some degree of bias to the responses.

The responses from the survey were collated in SPSS and the open questions analysed using General Inductive Analysis (GIA) (Thomas 2006), an approach to Grounded Theory data analysis. As a result, the main themes within comments made for each question were identified. This analysis was conducted independently by each of the authors and the results compared to ensure reliability. A report was then produced, highlighting the main findings of the survey (O'Sullivan et al. 2014). ${ }^{2}$

\section{Background of Survey Respondents}

Of the 1633 respondents, four did not indicate their gender, so their responses will not be considered further in this paper; of the remaining 1629 students, 939 (57.6\%) were male students and $690(42.4 \%)$ were female students.

The breakdown of responses from each institute can be seen in Table 1. It should be noted that the number of first-year service mathematics students in each institute varies considerably, and not all institutes target all first-year service mathematics students in their provision of mathematics support. However, based on the number of first-year

\footnotetext{
${ }^{1}$ Universities offer Ordinary and Honours Bachelors degrees, plus postgraduate programmes. IoTs also offer Higher Certificate programmes, and may not offer postgraduate [http://www.citizensinformation. ie/en/education/third_level_education/colleges_and_qualifications/third_level_education_in_ireland.html].

${ }^{2}$ Note that some of the findings of this paper have previously been reported in the report (O'Sullivan et al. 2014), but these are expanded upon here with a more detailed discussion.
} 
Table 1 Breakdown of student respondents per higher education institute in the survey

Respondents

$\begin{array}{ll}\text { University } & 207 \\ \text { Dublin City University } & 345 \\ \text { Maynooth University } & 90 \\ \text { National University of Ireland Galway } & 295 \\ \text { University College Dublin } & 263 \\ \text { University of Limerick } & \\ \text { Institute of Technology } & 254 \\ \text { Institute of Technology Tallaght } & 83 \\ \text { Institute of Technology Carlow } & 34 \\ \text { Institute of Technology Blanchardstown } & 58 \\ \text { Institute of Technology Tralee } & 1629 \\ \text { Total } & \end{array}$

students registered in relevant discipline areas for that year (Higher Education 2013), a minimum overall response rate of $25 \%$ for universities and $28 \%$ for institutes of technology can be calculated for the survey.

As well as being based in nine different institutions, these students were studying a range of discipline areas, which for analysis have been divided into six areas: Science, Engineering, Business, Arts, Education and Computing, as shown in Table 2.

Clearly, some of these areas would be more mathematically intensive than others, but all contain some modules of service mathematics. There is a significant association between gender and discipline area with a $p$-value $<0.001$ (chisquared $=175.5,5 \mathrm{df}$ ). As would be expected, this is particularly pronounced in disciplines such as Engineering and Computing (see Table 2), which are traditionally male-dominated in Ireland, as is the case in our sample. This compares with a national picture of 85 and $78 \%$ male respectively for Engineering and Computing undergraduates (Higher Education 2012, p. 56). The Education students in question were all studying to be secondary school teachers, rather than primary; a recent government report in Ireland showed $60 \%$ of secondary teachers are female, figures which are in line both with our sample and with international averages (O’Connor 2007, p. 10).

Table 2 Breakdown of survey respondents by discipline area and gender. Note that five students did not declare their discipline area, so $n=1624$ for this table

\begin{tabular}{llllllll}
\hline & Science & Engineering & Business & Arts & Education & Computing & Total \\
\hline Male & 292 & 204 & 241 & 28 & 32 & 142 & 939 \\
& $(50.43 \%)$ & $(86.81 \%)$ & $(49.9 \%)$ & $(41.79 \%)$ & $(35.96 \%)$ & $(83.04 \%)$ & $(57.82 \%)$ \\
Female & 287 & 31 & 242 & 39 & 57 & 29 & 685 \\
& $(49.56 \%)$ & $(13.19 \%)$ & $(50.1 \%)$ & $(58.21 \%)$ & $(64.04 \%)$ & $(16.96 \%)$ & $(42.18 \%)$ \\
Total & 579 & 235 & 483 & 67 & 89 & 171 & 1624 \\
\hline
\end{tabular}


In terms of prior mathematical achievement, $96 \%$ of respondents provided a Leaving Certificate level and grade for mathematics. The Leaving Certificate is the terminal examination taken by pupils at the end of secondary school in Ireland and is used as a gatekeeper examination for access into higher education, with students being awarded "points" from their best six subjects, and each degree programme requiring a certain number of points to obtain a place. Mathematics is a compulsory subject for students and can be taken at three levels: Higher, Ordinary and Foundation. Generally, a minimum of Ordinary Level mathematics would be needed for most degree programmes, and this is reflected among respondents with only 18 of the 1562 students who provided their results in the survey having studied mathematics at Foundation Level. In this survey, gender and Leaving Certificate mathematics level are independent with a $p$-value of 0.4 (chi-squared $=1.8,2 \mathrm{df}$ ), with very similar proportions of male and female students studying mathematics at each level. However, gender and overall Leaving Certificate mathematics grade at each level are significantly linked with a $p$-value $<0.001$ (chi-squared $=40.6,8 \mathrm{df}$ ), with twice as many male respondents receiving an A-grade in Higher Level (HA) as female (6\% compared to $3 \%$ ), while at Ordinary Level, this trend reverses with $14 \%$ of male students receiving an A-grade (OA) compared to $22 \%$ of female students. This is generally reflective of (if more pronounced than) the national trend that year (see statistics from www.examinations. ie), where (considering only students who passed the examination, as these are the only ones who would be included in our survey), $3.5 \%$ of male students and $2 \%$ of female students obtained a HA, while $8 \%$ of male students and $12 \%$ of female students obtained an OA.

\section{Engagement with Mathematics Support}

Students were asked if they had made use of the mathematics support available within their own institution and $35.9 \%$ of respondents had done so. There is a significant association between gender and the use of mathematics support with a $p$-value $<0.001$ (chi-squared $=41.9,1 \mathrm{df}$ ), with $29.5 \%$ of male respondents attending mathematics support compared to $45.1 \%$ of female respondents. This is the result that initially suggested that gender differences in mathematics support usage be further examined, leading to the postulation of the four research questions that we aim to address in this paper.

As a result, a binomial logistic regression was performed to further explore the effects of gender, LC level and grade, mature student status, degree, and institution attended upon the likelihood that a student engaged with mathematics support. The resulting model was statistically significant with a $p$-value $<0.0005$. The independent variables in the model together accounted for $48.1 \%$ of the explanation of why a student engaged with mathematics support. Controlling for differences in the other factors named above, being a female student increased the likelihood of engaging with mathematics support by 2.49 times. This result was statistically significant with a $p$ value $<0.0001$.

Other variables which had a significant impact upon engagement with mathematics support included the institution attended and the student's prior mathematical attainment, as well as smaller effects from mature student status and degree programme 
studied. However, given that these factors have previously been explored, both in a range of other studies (e.g. Faulkner et al. 2016; Faulkner et al. 2010), as well as in a general report on this study (O'Sullivan et al. 2014), the focus of this paper will be the differences in engagement based on gender.

\section{Gender Differences Among Students Who Used Mathematics Support}

Our regression model found that students' prior mathematical achievements had an impact upon their engagement with mathematics support, as might have been expected, as those with lower grades are in greater need of support. Although gender and Leaving Certificate mathematics levels were independent for the full cohort of students in this study, when focussing only upon those who used mathematics support there is a significant association between the two ( $p$-value $=0.02$, chi-squared $=7.8,2 \mathrm{df}$ ). The most pronounced difference occurs between male and female students who have Higher Level Leaving Certificate mathematics, with $17.25 \%$ of male respondents at this level using mathematics support, compared with $47.09 \%$ of female respondents at the same level. If we look more specifically at the grades obtained by students within each level, there is a stronger association again ( $p$-value $<0.001$, chi-squared $=39.7$, $7 \mathrm{df}$ ). The spread of grades is shown in Fig. 1, where it can be seen that female students for all levels and grades, except $\mathrm{OB}$, attend at a higher percentage rate than male students.

Again, the discipline the students are studying was a significant factor in our regression model, and here again there is a significant association between gender and discipline studied for those using mathematics support ( $p$-value $<0.001$, chisquared $=76.2,5 \mathrm{df}$ ). This is shown in Fig. 2. From this figure, it can be seen that female students from Science, Arts and Education are more likely to attend than male students, while the proportions are almost equal in Engineering and Business.

An answer to our first research question is provided by the fact that there are significantly different levels of engagement between male and female students with mathematics support. Both female students in similar disciplines to male students, and

\section{Usage of mathematics support by gender and grade}

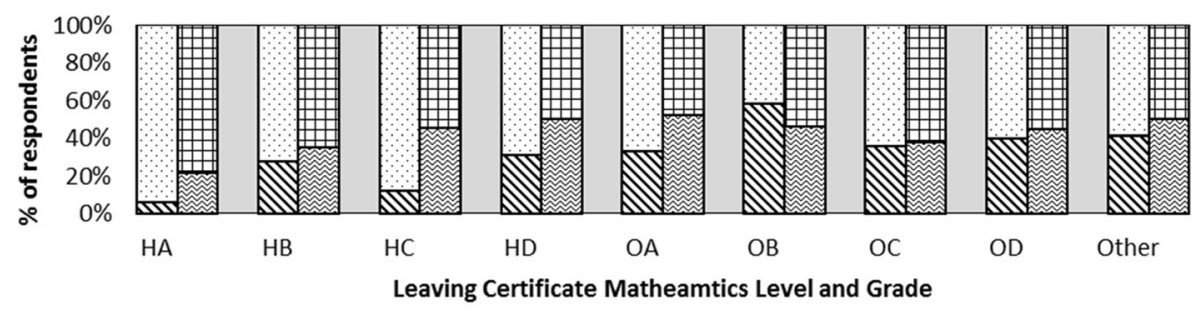

\$Male attendee $\square$ Male non-attendee :

Fig. 1 Percentage of students of each gender and Leaving Certificate mathematics grade who used mathematics support. Note that HA stands for an A-grade at Higher Level, while OA stands for an A-grade at Ordinary Level, and so on. "Other" includes students who did not complete the Leaving Certificate, some of whom are international students with different qualifications. (males $n=276$, females $n=309$ ) 


\section{Usage of mathematics support by gender and discipline}

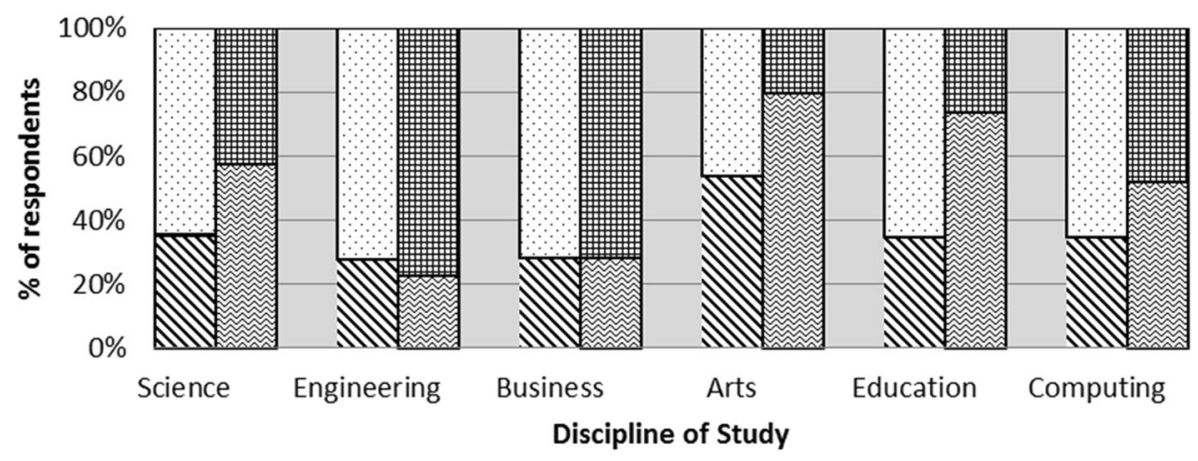

NMale attendee $\square$ Male non-attendee 国Female attendee $\mathbf{\theta}$ Female non-attendee

Fig. 2 Percentage of students from each discipline who used mathematics support, given as a proportion of students of each gender in the discipline within our study (males $n=276$, females $n=309$ )

female students with equal or higher levels of prior mathematical attainment to male students, demonstrate higher levels of attendance. To investigate possible reasons for this difference, it was important that the reasons given by students of both genders for using mathematics support be further considered to determine whether any variation could be perceived in their responses, and whether themes in line with the previouslydiscussed research on confidence and self-perception issues for female students in relation to mathematics (Fennema 1980; Nurmi et al. 2003; Jones and Smart 1995) would also emerge in our data.

\section{Gender Differences in Reasons for Using Mathematics Support}

Students who had chosen to use mathematics support were asked an open-ended question on why they first decided to do so (see Appendix). There were 555 comments in response to this question, of which 303 were from female students and 252 from male students. These responses were coded into six main themes: Assignments / Exams; Extra help; Improve understanding; Mathematics difficult; Background / Ability; Struggling. Each comment is placed under the one main theme it most closely aligned to. A chi-squared test of independence on this data showed that there was a significant association between gender and the themes given with a $p$-value $<0.001$ (chi-squared $=21.6,6 \mathrm{df}$ ), providing a partial answer to the second research question regarding whether students' reasons for using mathematics support differ by gender.

There were a greater number of comments from female respondents for this question; therefore, a clearer picture can be obtained by considering the proportion of comments from each gender that fell under each theme. This is done in Fig. 3, in which the percentages are shown for each gender in each theme.

The most striking difference can be seen where nearly half of female respondents identified assignments or upcoming examinations as being the main reason they decided to use mathematics support; this compares with only a quarter of male 
Why did you first decide to use mathematics support?

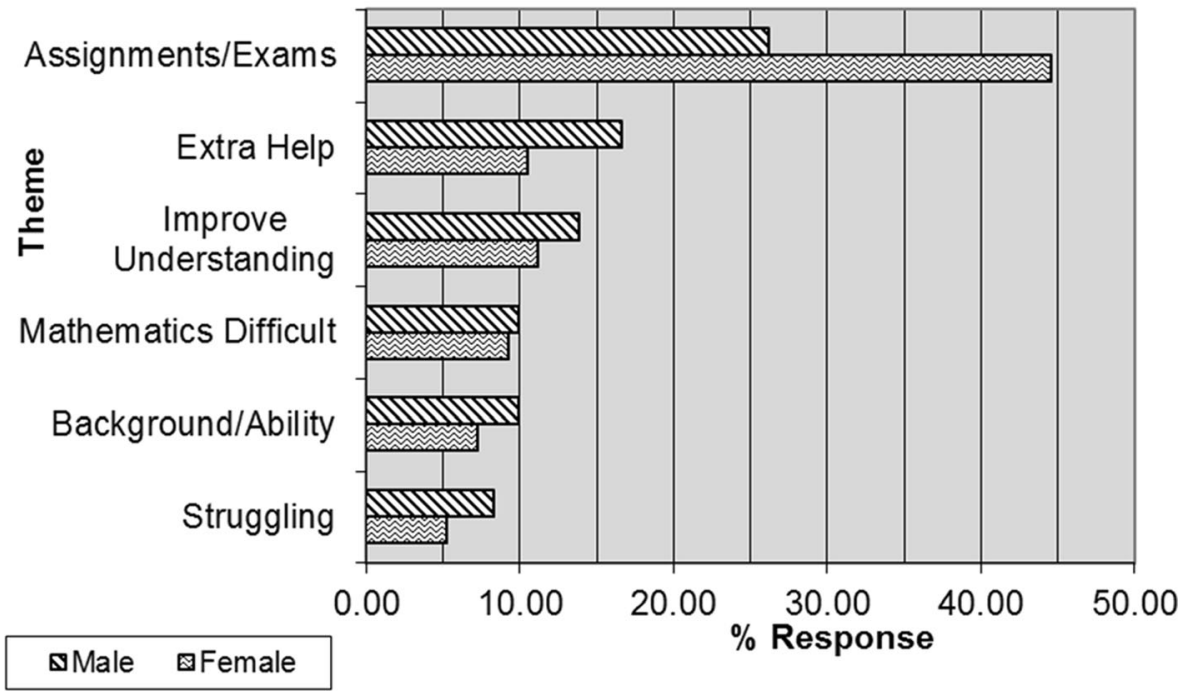

Fig. 3 Percentage of students of each gender whose answers to the question "Why did you first decide to use mathematics support?" fell into each of the six main themes identified (males $n=252$, females $n=303$ )

respondents citing this reason. These students typically made comments such as " $I$ couldn't do the maths assignment" or "I had a class test coming up".

Male students were more likely than female students to mention a generic need for extra help. Some of these students were non-specific about the help they required ("Because I needed some help") while others gave more particular information such as "To get help at the start of the year" or "Because I needed help with maths and it was there and free".

The difference between the genders was less striking in the remaining categories (improving understanding; mathematics difficult; background; struggling). Indeed, contrary to what might have been expected from the prior research in this field, female students were slightly less likely than male students to mention their prior background in mathematics or their perceived ability as a primary incentive for mathematics support.

\section{Gender Differences in the Potential Impact of Mathematics Support}

In addition to the open-ended question on why students used mathematics support in the first place, there were a number of survey questions about the potential impact of mathematics support, from the students' point-of-view. In one such question, students were asked to rate how mathematics support has helped them to cope with the mathematical demands of their course. Their responses showed significant differences based on gender $(p$-value $=0.02$, chi-squared $=12,4 \mathrm{df})$. Figure 4 gives the relative percentages of male and female respondents for this question (note that the samples in each group are similar in size, with 245 male respondents and 284 female respondents).

As can be seen in Fig. 4, female respondents were more likely than male to report that mathematics support had been a "huge help" in coping with the mathematical 


\section{Rate how mathematics support has helped you to cope with the mathematical demands of your course}

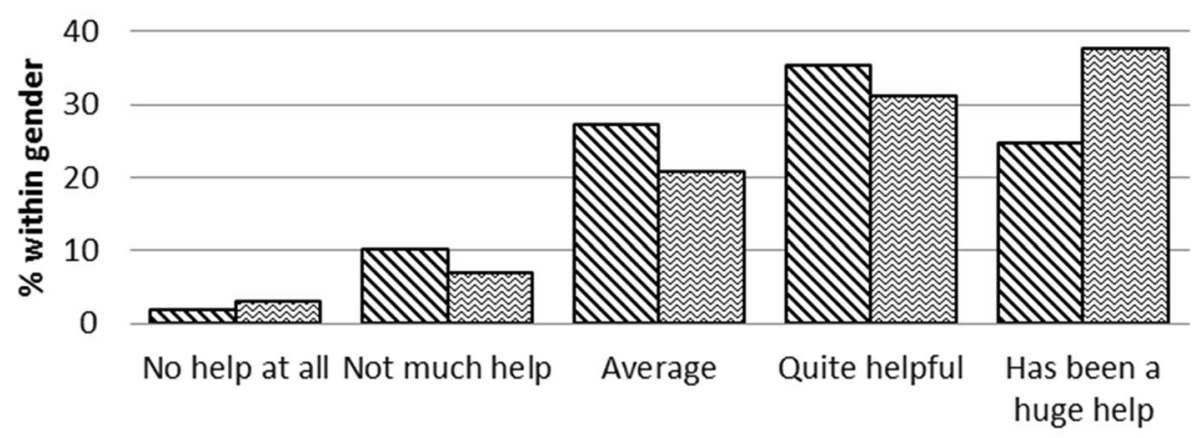

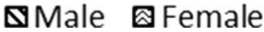

Fig. 4 Student ratings by gender in response to the question "Rate how mathematics support has helped you to cope with the mathematics demands of your course". (males $n=276$, females $n=309$ )

demands of their course or "no help at all", while male respondents were more likely to choose one of the three middle options ("not much help", "average" or "quite helpful").

However, responses to all other similar questions about impact were independent of gender, showing no significant differences between male and female respondents. These included whether students had considered dropping out of their degree programme due to mathematical difficulties ( $p$-value $=0.3$, chi-squared $=0.95,1 \mathrm{df}$; whether mathematics support had improved their confidence in mathematics ( $p$-value $=$ 0.7 , chi-squared $=2.2,4 \mathrm{df}$ ); and whether it had impacted upon their performance in examinations ( $p$-value $=0.4$, chi-squared $=5,5 \mathrm{df}$ ). So in response to the third research question posed in this paper, it seems that overall, male and female students do not report a differing impact upon themselves having used mathematics support, with students of both genders appearing to benefit equally once they engage with the services provided. This is an important finding in that it can provide some reassurance to those in charge of such services that there does not appear to be an inherent bias towards one gender within mathematics support; however, the question remains as to why male students are not engaging at similar levels to female students, and so the final research question of gender differences in the non-users of mathematics support is considered next.

\section{Gender Differences Among Students Who Did Not Use Mathematics Support}

While there should always be a significant cohort of students for whom mathematics support is unnecessary, the differences in attendance rates between male and female students with similar prior mathematical achievements and studying the same subject areas means that it is of particular interest to ascertain the opinions of those who did not 
engage these services. As such, the group of 1052 respondents (672 male and 380 female) to this survey who did not use mathematics support require specific attention. The mathematical background and discipline of origin for these students can be seen in Figs. 1 and 2 in the previous section under "male non-attendees" and "female nonattendees".

\section{Gender Differences in Reported Reasons for Not Using Mathematics Support}

Students who did not engage with mathematics support were asked why they had not done so. In this case, they were given a list of reasons to choose from, based on the most common responses given by students on individual mathematics support evaluations in various HEIs. The reasons given were: Do not need it; Times not suitable; Location unknown; Never heard of it; Afraid/Embarrassed; Hate Maths; Other; and the students were asked to choose the most suitable responses. Some of these reasons relate to issues that may differ from one institution to the next, based on the type of campus in question, the extent and suitability of the opening hours of mathematics support, local promotion efforts and so on. Where possible, any such effects are also taken into account below, although in many cases the sample sizes in question are too small from several of the institutions (when broken down by attendance, then gender, then theme) to allow for further meaningful analysis by institution.

For this question, there were 652 male respondents who made additional comments and 373 female. In Fig. 5, we can see the percentage of respondents of each gender who chose the reasons supplied in answer to the question "If you did not use mathematics support, why not?".

Given that students had the option of selecting more than one response here, the data was analysed by running a series of chi-squared tests on each of the seven options available and then performing the Bonferroni-Holm correction (Holm 1979) on the data, to control for the number of false positives that might otherwise appear. This correction is quite conservative and so we only see the most significant differences appearing in the results. This gives us a statistically significant difference between the

\section{Reasons for not using mathematics support}

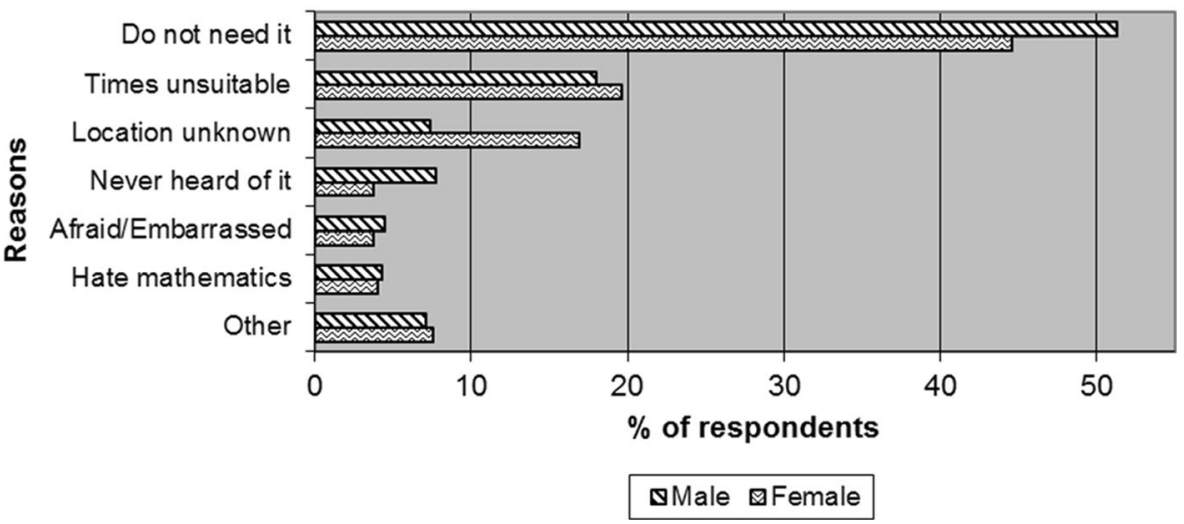

Fig. 5 Percentage of respondents of each gender who chose each of the above reasons in answer to the question "If you did not use mathematics support, why not?" (males $n=652$, females $n=373$ ) 
responses for men and women for two of the categories: "I did not know where it was" (adjusted $p=0.007,1 \mathrm{df}$ ) and "I never heard of the Mathematics Support Centre" (adjusted $p=0.024,1 \mathrm{df}$ ).

If we consider the responses in terms of frequencies, almost half (48\%) of students who had not availed of mathematics support felt that they did not need to, as shown in Table 3. Although there is a noticeable difference between the genders here; it is not as pronounced as we might have expected based on some of the research mentioned earlier, ending up with an adjusted $p$-value of 0.18 with 1 degree of freedom. The next most common response was that the times when support was available were not suitable, with $28 \%$ of respondents selecting this. A much higher proportion of women than men stated that they did not know where mathematics support sessions were held in their institutions (this was one of the two responses that showed up as significant in our conservative test). The majority of these responses came from two of the largest institutions involved in the study, with responses from the other institutions in single figures. Male students were twice as likely as female students to say that they had never heard of the service, though the overall percentage of students choosing this response was small (6\% in total). Again, this result was significant, and heavily influenced by responses from three institutions: one large university and two IoTs in which there was limited mathematics support provision. The proportions were very similar in both genders when it came to choosing options such as "afraid/embarrassed" and "I hate mathematics".

However, if we then omit those students who chose more than one option and look at the 686 students who selected exactly one reason for non-attendance, a statistically significant difference emerges overall between male and female

Table 3 Student responses to the question: "If you did not use mathematics support, why not? Tick as many as apply"

\begin{tabular}{|c|c|c|c|c|}
\hline $\begin{array}{l}\text { Q16 response } \\
\text { options }\end{array}$ & $\begin{array}{l}\text { No. of } \\
\text { responses }\end{array}$ & $\begin{array}{l}\text { As } \% \text { of all } \\
\text { non-engaging } \\
\text { students }\end{array}$ & $\begin{array}{l}\text { No. of responses } \\
\text { from males }(\mathrm{M}) \\
\& \text { females }(\mathrm{F})\end{array}$ & $\begin{array}{l}\text { As } \% \text { of male / } \\
\text { female respondents }\end{array}$ \\
\hline \multirow[t]{2}{*}{ Do not need help } & \multirow[t]{2}{*}{501} & \multirow[t]{2}{*}{$48.12 \%$} & $335(\mathrm{M})$ & $50.68 \%$ of males \\
\hline & & & $166(\mathrm{~F})$ & $43.92 \%$ of females \\
\hline \multirow[t]{2}{*}{ Times do not suit } & \multirow[t]{2}{*}{295} & \multirow[t]{2}{*}{$28.33 \%$} & $175(\mathrm{M})$ & $26.48 \%$ of males \\
\hline & & & $120(\mathrm{~F})$ & $31.75 \%$ of females \\
\hline \multirow[t]{2}{*}{ Did not know where it was } & \multirow[t]{2}{*}{186} & \multirow[t]{2}{*}{$17.87 \%$} & 99 (M) & $14.98 \%$ of males \\
\hline & & & $87(\mathrm{~F})$ & $23.02 \%$ of females \\
\hline \multirow[t]{2}{*}{ Hate Maths } & \multirow[t]{2}{*}{151} & \multirow[t]{2}{*}{$14.51 \%$} & $96(\mathrm{M})$ & $14.52 \%$ of males \\
\hline & & & $55(\mathrm{~F})$ & $14.55 \%$ of females \\
\hline \multirow[t]{2}{*}{ Embarrassed or afraid to go } & \multirow[t]{2}{*}{119} & \multirow[t]{2}{*}{$11.43 \%$} & $67(\mathrm{M})$ & $10.14 \%$ of males \\
\hline & & & $52(\mathrm{~F})$ & $13.76 \%$ of females \\
\hline \multirow[t]{2}{*}{ Never heard of the MLC } & \multirow[t]{2}{*}{87} & \multirow[t]{2}{*}{$8.36 \%$} & $68(\mathrm{M})$ & $10.28 \%$ of males \\
\hline & & & $19(\mathrm{~F})$ & $5.03 \%$ of females \\
\hline \multirow[t]{2}{*}{ Other Reason } & \multirow[t]{2}{*}{133} & \multirow[t]{2}{*}{$12.78 \%$} & $82(\mathrm{M})$ & $12.41 \%$ of males \\
\hline & & & $51(\mathrm{~F})$ & $13.49 \%$ of females \\
\hline
\end{tabular}


responses $(p=0.006$, chi-squared $=18.2,6 \mathrm{df})$. As this was also the case for students who used mathematics support, this provides an answer to our second research question, showing that there are a number of areas, as reported above, in which male and female students report different reasons for using or not using mathematics support. Further details and analysis of the full scope of student comments regarding engagement can be found in (Mac an Bhaird et al. 2013).

\section{Reasons Which Would Encourage Usage of Mathematics Support}

Students who did not attend were asked "What would encourage you to use mathematics support if you needed to?" There were 676 responses, 419 from male students and 257 from female students. Students' responses were again categorised into the main themes outlined in Fig. 6, and responses were categorised under only one theme. There is a statistically significant difference between the responses for men and women with a $p$-value $<0.001$ (chi-squared $=32.8,8 \mathrm{df}$ ). Thus, we may be able to use this information to determine whether different approaches should be taken to encourage male and female non-users of mathematics support to engage with the service, as postulated in our fourth research question.

The most pronounced differences between the genders were in the top two responses. In the first of these, where ten percentage points separated the genders, $26 \%$ of respondents said that they would attend mathematics support if they themselves felt they needed to, with comments such as "I would use it if I needed it without hesitation". Twice as many women as men $(17 \%$ of respondents overall) requested opening times that suited them better, with some being nonspecific ("If the times suited better") while others gave a range of suggestions

\section{What would encourage you to use mathematics support if you needed to?}

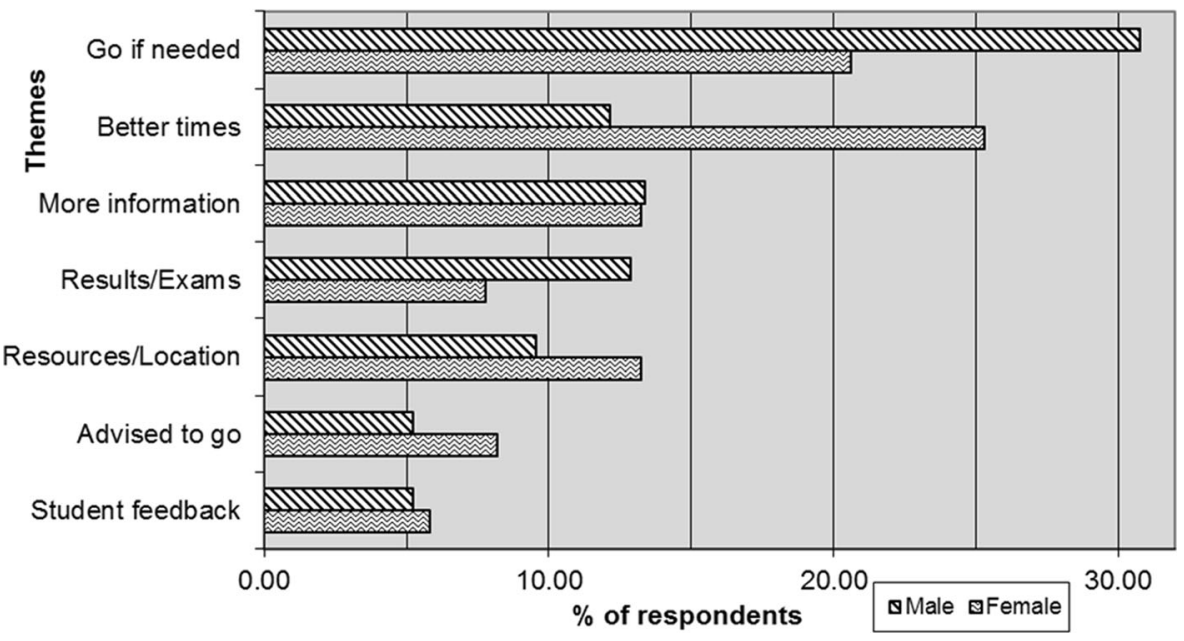

Fig. 6 Percentage of respondents of each gender whose responses fell under each of the main themes listed above when asked "What would encourage you to use mathematics support if you needed to?" (males $n=419$, females $n=257$ ) 
regarding the hours that would be more appropriate, such as "If the times were earlier in the day, it would encourage me to go", "If there were more hours during the day when I'm in college already, it would suit better" or "Evening opening hours instead of daytime opening hours". Considering these comments in relation to the 29 part-time students only, seven of these mentioned opening times, two of whom were female (the only two female part-time students in the sample, both from the same institution). There were 85 mature students who did not engage with mathematics support, of whom 60 were female; eight mature students mentioned opening times, of whom only one (a part-time student) was female. Thus, although a quarter of female students who had not engaged with mathematics support mentioned better opening hours as an encouragement to attend, there is no evidence that this was particularly the case for mature students and the sample of part-time female students is too small to warrant any conclusions being drawn. It would appear that appropriate opening times are a major concern for full-time traditional female students.

An equal split of $13 \%$ of each gender felt they needed more information about mathematics support, both in terms of advertising the existence and location of the service ("More advertisement on where and when it's on.") and in terms of specific information of how the support would operate ("Knowing more of what's involved and what I would be spending my time doing.").

It is of interest, given that assignments or upcoming examinations were cited as the main reason for attendance for $45 \%$ of the female students who used mathematics support, that only $8 \%$ of female students (and $13 \%$ of male students, giving $11 \%$ of respondents overall) felt that obtaining poor results in an assessment ("If I wasn't doing well and getting bad results, then I would need help") or concern about results in a forthcoming examination ("If I thought I was going to fail") would be a driving force for them to attend mathematics support. In fact, more female students cited a need for specific resources being in place instead ("Solutions and sample papers", "A Moodle page in maths" and "If they could possibly create easy or simplified notes on certain topics that are thorough and contain many different examples.") or commented on the physical setting of the support centre ("More central location") than mentioned examinations.

More female students than male students would like to be advised or incentivised to attend mathematics support, usually by a lecturer ("If I was advised by my lecturer that it would be useful to me if I needed help" or "If you got a percentage of final grade for going"). Again, somewhat surprisingly, only $5 \%$ of each gender mentioned feedback from other students ("If I heard good reviews of it") as being a primary potential motivator for them to attend, where it would often be imagined that peer influence would be a more important factor than is shown in this response. In general, students with a stronger mathematical background were more likely to say they would go if they needed to, while those with a weaker background were more likely to comment on the structures of the mathematics support available (Mac an Bhaird et al. 2013).

\section{Further Discussion}

The regression analysis conducted found that female students were two and a half times more likely than male students to engage with mathematics support, when controlling 
for factors such as prior mathematical attainment, degree programme and institution attended. The difference was most striking in terms of students who had studied Higher Level Leaving Certificate mathematics, where $47 \%$ of women with this level attended, compared to $17 \%$ of men. This result supports the wealth of literature in existence on the lower mathematical self-confidence of female students compared to male students, even with similar background and achievement levels (Mura 1987; Fennema 1980; Nurmi et al. 2003; Jones and Smart 1995; Guimond and Roussel 2001). Female students' engagement with mathematics support systems on this scale can in fact be seen as a possible proxy for lack of confidence in their mathematical abilities. It is interesting, however, that no clear evidence of this greater lack of confidence emerged in comments made by female students, who largely focussed on more tangible issues such as room location, imminence of examinations or timetable issues.

Although mathematics departments are traditionally viewed as "male domains" (Brandell and Staberg 2008), mathematics support centres do not seem to be similarly viewed by the students in this study. Indeed, it seems to be easier for female students to ask for help in this field than male students, which may be explained by the fact that "male students... are especially concerned not to appear incompetent in mathematics" (Skaalvik and Skaalvik, p. 251) and engaging with a mathematics support service may be seen by some students as tantamount to just such an admission. However, it is also possible that female students might be more liable to seek help in general than male students, as found in the work of Kessels and Steinmayr (2013), who found that "girls reported better overall attitudes towards help seeking than boys" (p. 238), although the issue is complex.

Another theory is that "completing homework, studying, being organized...(are) behaviors that are considered feminine (and) women and girls may thus be more likely to enact these behaviors, and they may be reinforced for doing so" (Cheryan 2012, p. 187), which may make women more likely to make use of whatever academic supports are available. Equally, the discourse on mathematics as a "male domain" (Brandell and Staberg 2008) may in fact motivate some female students (from a feminist viewpoint) to engage with support services in mathematics to achieve good grades, as per the findings of Leaper et al. (2012) who state that "learning about feminism and endorsing gender equality were positively associated with girls' motivation in math and science" (p. 280).

The finding from our student cohort that women were far more likely than men to cite upcoming examinations as a reason for engaging with mathematics support aligns well with the work of Kosmala-Anderson and Wallace (2007). They found that female students are more likely to self-report pre-examination stress and more likely to use "active coping with problem" to resolve this and quote one (female) participant in their study as saying "When I face the problem I would rather do anything to deal with it than wait until it all somehow gets sorted out" (KosmalaAnderson and Wallace 2007, p. 339). The fact that female students were less likely than male students to cite upcoming examinations as an incentive to attend if they had not previously attended (with only $11 \%$ of all students mentioning it in this context), while somewhat unexpected, was likely to have been influenced by the timing of the survey, which took place early in the second semester, with few examinations imminent. Male students were more likely to mention their need for extra help as their motivation for having used mathematics support, but also more 
likely to say they did not need extra help if they had not attended. Female students were much more likely to say they did not know the location of the support available if they had not attended, and these female students were primarily located in two of the largest universities in the sample. This warrants further attention in future research to ascertain possible reasons for this difference.

Although female students were more likely to state that mathematics support had been a huge help in coping with the mathematics demands of their course, overall there was no evidence of gender disparity in terms of the self-reported impact of mathematics support from the student perspective. One possible reason for the difference reported in terms of coping with mathematics may be found in the work of Solomon et al. (2011) who state that "the dynamics of the support centres provide a context in which all students can take up empowered positions with respect to mathematics...this may be particularly the case for women in providing new ways of being both mathematical and female" (Solomon et al. 2011, p. 580-582). Importantly, however, for those who work in mathematics support, students themselves (at least those in this study) do not report any difference in the level of help they perceive they obtain.

When considering how to motivate non-engaging students to attend if needed, in order to determine if there were specific ways mathematics support could be made more appealing to students who do not currently engage, results were mixed. While equal numbers of men and women cited the unsuitability of the timetabling of mathematics support as a reason for non-attendance, twice as many women as men felt that more suitable times would make them more likely to attend. Male students were far more likely to say that they would attend if they needed to, although overall this was true of students of both genders with higher grades on entry, while weaker students were more likely to comment on specific structures within mathematics support. Female students were no more likely to cite peer influence, in contrast to the findings of Han and Li (2009). In fact, peers were ranked very low by both genders in terms of motivation for attending mathematics support if they had not previously done so, although Grehan et al. (2016) found that the influence of friends emerged as a strong factor among students who used mathematics support. No clear specific suggestions that could be acted on by support staff emerged from male students who were not engaging with mathematics support as to what would make them likely to attend in greater numbers. This suggests that the work currently undertaken in mathematics support centres should be continued in its present format, while allowing for the fact that other approaches (such as online support, group study sessions or peer-support systems, for example) may also be worth exploring to enable as many students as possible to benefit from such a service.

\section{Conclusions}

This work was motivated by the observation that a greater percentage of female respondents than male respondents attended mathematics support services when the 
results of a survey of over 1600 students from nine HEIs in Ireland were analysed. There were four research questions considered in this paper, which explored how engagement levels with mathematics support compare between male and female students, whether different reasons were reported by male and female students for either using or not using mathematics support, if they perceived the impact of the support they received differently, and if they suggested different reasons that might motivate them to engage if needed.

Female students were two and a half times more likely to engage with mathematics support, when controlling for factors such as prior mathematical attainment, degree programme and institution attended. However, although we have proposed a number of possible reasons for this, no single definitive answer emerged (and possibly none exists). Indeed, it is unclear how many of the male students who deemed that they did not need to engage with mathematics support were correct in this assumption and how many were overestimating their likely grades in mathematics (although the latter appears probable, given the work of Mura 1987 and Guimond and Roussel 2001). Encouragingly, among those students who did engage with mathematics support, there was no reported difference between male and female students with regards to the impact of the support upon their studies, with both groups deeming that they benefitted from the experience.

Students, in particular female students, who did not engage with mathematics support mentioned that they would be encouraged to attend if advised to do so. Lecturers can play a part in encouraging students to attend mathematics support by mentioning the services available regularly, but particularly at key times such as when introducing topics they know cause difficulties or when returning assignments or inclass assessment marks. In general, non-engaging students of both genders with higher grades were more likely to say they would attend if they needed the help, so this form of more targeted in-lecture encouragement and promotion may reach some of those struggling students who do not currently engage. It would appear that the expansion of existing mathematics support services, allowing for a more expansive timetable, greater advertising of the location and availability of services, and more topic-specific revision resources would be of benefit to all students.

Acknowledgments Some of the findings of this paper have previously appeared in a report (O'Sullivan et al. 2014), along with slightly modified versions of Figs. 1, 2, 3, 4, 5, and 6 and Tables 1, 2, and 3, which are used here with the permission of the copyright holder.

\section{Compliance with Ethical Standards}

Funding Funding was received towards this project from the All-Ireland Society for Higher Education (AISHE) and the National Digital Learning Repository (NDLR).

Appendix: Mathematics Support Survey We are looking for your feedback on the Mathematics Support Centre (MSC) and its services. This evaluation is designed to help us to improve the MSC for you and other students. Even if you have not used the MSC's services, your feedback is important. 


\section{Section A}

1. Degree Programme:

$\begin{array}{lllll}\text { 2. Year: Certificate } & \mathbf{1}^{\text {st }} \text { year } & \mathbf{2}^{\text {nd }} \text { year } & \mathbf{3}^{\text {rd }} \text { year } & \mathbf{4}^{\text {th }} \text { year Postgrad } \\ \text { Student Category: } & \text { Full-time } & \text { Part-time } & \\ \text { 3. } & \text { Gender: } & \text { Male } & \text { Female }\end{array}$

Gender:

4. Leaving Certificate Mathematics Level (if applicable):
Higher
Ordinary
Foundation
Other

5. Leaving Certificate Mathematics Grade (if applicable):
Leaving Cert 1991 or before:
A
B C
D E Other

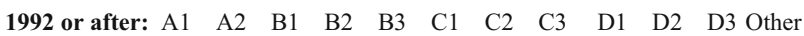

6. If you started off doing Leaving Certificate Higher Level Mathematics, but changed to Ordinary Level, roughly when did that happen? (Please circle)

Before Christmas in $5^{\text {th }}$ year Before the end of $5^{\text {th }}$ year

Before Christmas in $6^{\text {th }}$ year After the Mocks in $6^{\text {th }}$ year N/A

7. Are you registered as a mature student? Yes No

8. Have you used any of the Maths Support Centre's services (drop-in centre, support workshops, online courses)? Yes No

If $\underline{\text { YES}}$, please proceed to $\underline{\text { Section } \mathrm{B}}$. If $\underline{\mathrm{NO}}$, please proceed to $\underline{\text { Section } \mathrm{C}}$

\section{Section B (Students who used the MSC)}

9. Why did you first decide to use the MSC or its services?

10. Being as honest as you can, rate the following services that you have used below on a scale of 1 to 5 where $1=$ Not at all Worthwhile and $5=$ Extremely Worthwhile
Drop-In Centre
Comments/Suggestions:
Online Courses
Comments/Suggestions:
Workshops
Comments/Suggestions:

11. Did you ever consider dropping out of your course/college because of mathematical difficulties? Yes No Comments:

12. If yes, has the MSC influenced your decision not to drop out? Yes No Comments:

13. Rate how the MSC has helped your confidence in maths on a scale of 1 to 5 where 1 = Not at all Helpful and 5 = Extremely Helpful. Comments:

14. Rate how the MSC has impacted on your maths performance (in exams/tests) so far on a scale of 1 to 5 where $\mathbf{1}=$ No impact at all and $\mathbf{5}=$ Has had a large impact.

Comments:

15. Having used some of the MSC's services, rate on a scale of 1 to 5 how you feel the MSC has helped you cope with the mathematical demands of your course where $1=$ No help at all and $\mathbf{5}=$ Has been a huge help.

Comments:

\section{Section C (Students who did not use the MSC)}

16. If you did not use the MSC, why not? Tick as many reasons as apply:

$\square \quad$ I do not need help with Maths

I never heard of the Mathematics Support Centre

I did not know where it was

The times do not suit me

I was afraid or embarrassed to go

I hate Maths

Other (please specify)

Comments:

17. What would encourage you to use the MSC and its services if you needed to? 


\section{References}

Brandell, G., \& Staberg, E. M. (2008). Mathematics: a female, male or gender-neutral domain? A study of attitudes among students at secondary level. Gender and Education, 20(5), 495-509.

Carroll, C., \& Gill, O. (2012). An innovative approach to evaluating the University of Limerick's Mathematics Learning Centre. Teaching Mathematics and its Applications, 31(4), 199-214.

Cheryan, S. (2012). Understanding the paradox in math-related fields: why do some gender gaps remain while others do not? Sex Roles, 66, 184-190.

Croft, A. C. (2000). A guide to the establishment of a successful mathematics learning support centre. International Journal of Mathematical Education in Science and Technology, 31, 431-446.

Devine, A., Fawcett, K., Szucs, D., \& Dowker, A. (2012). Gender differences in mathematics anxiety and the relation to mathematics performance while controlling for test anxiety. Behavioral and Brain Functions, 8, 33. http://www.behavioralandbrainfunctions.com/content/8/1/33.

Faulkner, F., Hannigan, A., \& Gill, O. (2010). Trends in the mathematical competency of university entrants in Ireland by leaving certificate mathematics grade. Teaching Mathematics and its Applications, 29(2), 76-93.

Faulkner, F., Fitzmaurice, O., \& Hannigan, A. (2016). A ten year examination of the mathematical performance and learning styles of mature students and traditional students in Ireland. Irish Educational Studies. In press.

Fennema, E. (1980). Sex related differences in mathematical achievement: where and why? In L. Fox, L. Brady, \& D. Tobin (Eds.), Women and the mathematical mystique. Baltimore: John Hopkins University Press.

Fennema, E. (2000). Gender and mathematics: What is known and what do I wish was known? Paper presented at the Fifth Annual Forum of the National Institute for Science Education, Detroit, Michigan. http://www.wcer.wisc.edu/archive/nise/News_Activities/Forums/Fennemapaper.htm

Forgasz, H. (2001). Mathematics : still a male domain? Australian findings. Annual Meeting of the American Educational Research Association (pp. 1-16). AERA, Seattle, Washington.

Forgasz, H., Leder, G. C., \& Kloosterman, P. (2004). New perspectives on the gender stereotyping of mathematics. Mathematical Thinking and Learning, 6(4), 389-420.

Gill, O., \& O’Donoghue, J. (2006). Exploring mathematics under-preparedness at third level in Ireland. In S. Moore et al. (Eds.), Keeping Students at University; The retention debate at third level (pp. 153-168). Dublin: Intersource Group Publishing.

Gill O., O’Donoghue, J., \& Johnson, P. (2008). An audit of mathematical support provisions in Irish third level institutes, CEMTL, University of Limerick. Available from http://www3.ul.ie/cemtl/pdf\%20 files/FullAudit.pdf

Gill, O., Mac an Bhaird, v., \& Ní Fhloinn, E. (2010). The origins, development and evaluation of mathematics support services. Irish Mathematical Society Bulletin, 66, 51-64.

Gillard, J., Robathan, K., \& Wilson, R. (2012). Student perception of the effectiveness of mathematics support at Cardiff University. Teaching Mathematics and its Applications, 31, 84-94.

Grehan, M., Mac an Bhaird, C., \& O'Shea, A. (2011). Why do students not avail of mathematics support? Research in Mathematics Education, 13(1), 79-80.

Grehan, M., Mac an Bhaird, v., \& O’Shea, A. (2016). Investigating students' levels of engagement with mathematics: critical events, motivations, and influences on behaviour. International Journal of Mathematical Education in Science and Technology, 47(1), 1-28.

Guimond, S., \& Roussel, L. (2001). Bragging about one's school grades: gender stereotyping and students' perception of their abilities in science, mathematics, and language. Social Psychology of Education, 4, 275-293.

Han, L., \& Li, T. (2009). The gender difference of peer influence in higher education. Economics of Education Review, 28(1), 129-134.

Higher Education Authority (2012). Higher education: Key facts and figures 2011-2012. [Online]. Available from http://www.hea.ie/sites/default/files/keyfactsfigures1112_0.pdf

Higher Education Authority (2013). About HEA [Online] Available from http://www.hea.ie/en/node/981

Holm, S. (1979). A simple sequentially rejective multiple test procedure. Scandinavian Journal of Statistics, 6 , 65-70.

Jones, L., \& Smart, T. (1995). Confidence and mathematics: a gender issue? Gender and Education, 7(2), 157-166.

Kessels, U., \& Steinmayr, R. (2013). Macho-man in school: toward the role of gender role self-concepts and help seeking in school performance. Learning and Individual Differences, 23, 234-240. 
Kosmala-Anderson, J., \& Wallace, L. M. (2007). Gender differences in the psychosomatic reactions of students subjected to examination stress. Electronic Journal of Research in Educational Psychology, $5(2), 325-348$.

Leaper, C., Farkas, T., \& Brown, C. S. (2012). Adolescent girls' experiences and gender-related beliefs in relation to their motivation in math-science and English. Journal of Youth and Adolescence, 41, 268-282.

Leder, G.C. (2001). Mathematics as a gendered domain: New measurement tools. Annual meeting of the American Educational Research Association. AERA, Seattle, Washington.

Mac an Bhaird, C., \& Lawson, D. (2012). How to set up a mathematics and statistics support provision. sigma. Coventry: Coventry University. Available from http://www.sigma-network.ac.uk/wpcontent/uploads/2012/11/51691-How-to-set-up...final .pdf

Mac an Bhaird, C., Morgan, T., \& O'Shea, A. (2009). The impact of the mathematics support centre on the grades of first year students at the National University of Ireland Maynooth. Teaching Mathematics and its Applications., 28, 117-122.

Mac an Bhaird, C., Gill, O., Jennings, K., Ni Fhloinn, E., \& O’Sullivan, C. (2011). The Irish Mathematics Support Network: its origins and progression. AISHE-J: The All Ireland Journal of Teaching and Learning in Higher Education, 3(2), 51.1-51.14.

Mac an Bhaird, C., Fitzmaurice, O., Ní Fhloinn, E., \& O’Sullivan, C. (2013). Student non-engagement with mathematics learning supports. Teaching Mathematics and its Applications, 32(4), 191-205.

MacGillivray, H. (2008). Learning support in mathematics and statistics in Australian universities - a guide for the university sector. Australian Learning and Teaching Council. Available from http://www.olt.gov. au/resource-learning-support-mathematics-guide-qut-2008

MacGillivray, H. (2009). Learning support and students studying mathematics and statistics. International Journal of Mathematical Education in Science and Technology, 40(4), 455-472.

Matthews, J., Croft, T., Lawson, D., \& Waller, D. (2012). Evaluation of mathematics support centres: a review of the literature. Loughborough: sigma Centre for Excellence in Mathematics and Statistics Support. Available from http://www.mathcentre.ac.uk/resources/uploaded/52487-evaluation-of-msc-7.pdf

McGuinness, S., Bergin, A., Kelly, E., McCoy, S., Smyth, E., \& Timoney, K. (2012). A study of future demand for higher education in Ireland. Research series number 30. Dublin: ESRI. https://www.esri. ie/pubs/RS30.pdf

Mura, R. (1987). Sex-related differences in expectations of success in undergraduate mathematics. Journal for Research in Mathematics Education, 18(1), 15-24.

Ní Fhloinn, E. (2009). The role of student feedback in evaluating mathematics support centres. Proceedings of the CETL-MSOR Conference 2009 (pp. 94-98). https://www.heacademy.ac. uk/sites/default/files/proceedings_2009_upload_0.pdf

Nurmi, A., Hannula, M., Maijala, H., \& Pehkonen, E. (2003). On pupil's self-confidence in mathematics: gender comparisons. In N. A. Pateman, B. J. Dougherty, \& J. Zilliox (Eds.), Proceedings of $27^{\text {th }}$ Conference of the International group for the Psychology of Mathematics Education (pp. 453-460).

O’Connor, M. (2007). Sé Sí: Gender in Irish Education. Dept. of Education and Science: Dublin. Available from http://www.education.ie/en/Publications/Statistics/Se-Si-Gender-in-Irish-Education-Introduction-toChapter-9.pdf

O’Sullivan, C., Mac an Bhaird, C., Fitzmaurice, O., \& Ní Fhloinn, E. (2014). An Irish Mathematics Learning Support Network (IMLSN) Report on Student Evaluation on of Mathematics Learning Support: Insights from a large scale multi-institutional survey. Limerick, Ireland. Available from http://supportcentre.maths.nuim. ie/sites/supportcentre.maths.nuim.ie.mathsnetwork/files/uploads/docs/IMLSNFinalReportPrePrinters.pdf

Parsons, S., Croft, A. C., \& Harrison, M. (2011). Engineering students' self-confidence in mathematics mapped onto Bandura's self-efficacy. Engineering Education, 6, 52-61.

Pell, G., \& Croft, T. (2008). Mathematics support - support for all? Teaching Mathematics and its Applications, 27(4), 167-173.

Perkin, G., Lawson, D., \& Croft, T. (2012). Mathematics learning support in Higher Education: the extent of current provision in 2012. Available from http:/www.mathcentre.ac.uk/resources/uploaded/52789-mls-in-uk.pdf

Skaalvik, S., \& Skaalvik, E. M. (2004). Gender differences in math and verbal self-concept, performance expectations, and motivation. Sex Roles, 50(3), 241-252.

Solomon, Y., Lawson, D., \& Croft, T. (2011). Dealing with "fragile identities": resistance and reconfiguring in women mathematics students. Gender and Education, 23(5), 565-583.

Symonds, R., Lawson, D., \& Robinson, C. (2008). Promoting student engagement with mathematics support. Teaching Mathematics and its Applications, 27(3), 140-149.

Thomas, D. (2006). A general inductive approach for analyzing qualitative evaluation data. American Journal of Evaluation, 27(2), 237-246. 